\title{
SHOULD WE PERFORM ROUTINE BIOPSY DURING PERCUTANEOUS VERTEBROPLASTY IN VERTEBRAL COMPRESSION FRACTURES?
}

\author{
๑ Özkan ÖZGER' ${ }^{1}$, ๑ Necati KAPLAN² \\ ${ }^{1}$ Istinye University Faculty of Medicine, Çanakkale Anadolu Hospital, Clinic of Neurosurgery, Çanakkale, Turkey \\ ${ }^{2}$ Rumeli University, Çorlu Reyap Hospital, Clinic of Neurosurgery, Tekirdağ, Turkey
}

\begin{abstract}
Objective: Percutaneous vertebroplasty (PVP) is widely used all over the world, especially in elderly patients for osteoporotic, traumatic, and pathological vertebral compression fractures (VCFs). Previous studies have reported incidental tumors in vertebral biopsy. However, whether a routine biopsy should be performed during PVP is controversial. The aim of this study was to evaluate the importance of routine biopsy during PVP in the treatment of VCF.

Materials and Methods: The patients who underwent PVP under sedo-analgesia for single or multi-level thoracolumbar vertebrae fracture were reviewed retrospectively between March 2015 and June 2019. The study included 87 patients with VCF. A hundred eleven vertebral levels were treated with PVP.Vertebral bone biopsy was performed in 67 (77.01\%) patients. These biopsy specimens were examined pathologically. The mean age of the patients was $74.18 \pm 9.08$ years (91-48 years), and 12 of them (17.91\%) were male and 55 (82.09\%) were female.

Results: Malignancy was detected in 3 patients (4.48\%). Two of them were multiple myeloma and the other one was renal cell carcinoma metastasis.

Conclusion: Bone biopsy during PVP procedures does not cause significant time loss or complications. Therefore, revealing the underlying pathology provides a great advantage to the patient and the surgeon. We recommend routine vertebral bone biopsy using a biopsy needle during the PVP procedure.
\end{abstract}

Keywords: Percutaneous vertebroplasty, vertebral bone biopsy, vertebral compression fractures

Level of Evidence: Retrospective clinical study, Level III

\section{INTRODUCTION}

Percutaneous vertebroplasty (PVP) procedures are used to alleviate pain in patients with osteoporosis and stable fractures. Vertebroplasty is also recommended for traumatic fractures, hemangiomas, and primary or metastatic tumors in the vertebral body ${ }^{(1)}$. Secondary osteoporosis may also occur after systemic lupus erythematosus, Cooley's disease, Paget's disease, metastatic lesions or corticosteroid use. Vertebral compression fractures (VCFs) may also develop due to these conditions. Most vertebral augmentation procedures are thought to result from osteoporosis. Therefore, bone biopsy is not performed ${ }^{(11)}$. The etiology of VCFs may change the treatment decision and method. The diagnosis of osteoporotic VCF before vertebral augmentation procedure is based on clinical findings and imaging methods but they sometimes cannot determine the true etiology of VCF. Previous studies of the vertebral augmentation procedure revealed incidental malignancies as a result of bone biopsy. Routine biopsy was not used in some of these studies ${ }^{(6,15)}$. The aim of this study was to analyze the results of routine vertebral bone biopsies obtained from all PVPs performed by a single surgeon in a single center.

\section{MATERIALS AND METHODS}

The records of 87 patients ( 73 females, 14 males) hospitalized for VCFs in the Neurosurgery Clinic of Çanakkale Anadolu Hospital between March 2015 and June 2019 were retrospectively reviewed. A hundred eleven PVP levels included T6 (2), T7 (3), T8 (3), T9 (2), T10 (3), T11 (10), T12 (25), L1 (25), L2 (15), L3 (11), L4 (6), and L5 (6). Vertebral bone biopsy was taken from 77.01\% ( $n=67)$ patients (55 females, 12 males) and referred to the department of pathology. Adequate biopsy was not obtained from $22.99 \%(n=20)$ patients. Therefore, the study was evaluated for 67 patients. The mean age of the patients was $74.18 \pm 9.08$ years (91-48 years) and 12 of them (17.91\%) were male and 55 (82.09\%) were female. All patients underwent one level vertebral body biopsy. Biopsy specimens sent to

Address for Correspondence: Özkan Özger, İstinye University Faculty of Medicine, Çanakkale Anadolu Hospital, Clinic of Neurosurgery, Çanakkale, Turkey Phone: +90 5077906639 E-mail: ozkanozger@hotmail.com Received: 10.08.2019 Accepted: 17.09.2019

ORCID ID: orcid.org/0000-0001-7257-8379 
the department of pathology from VCFs were histologically evaluated. These evaluations were noted retrospectively. The demographic characteristics of the patients are shown in Table 1. Patients with one or more VCFs had severe pain in the lumbar or thoracic region despite medical treatment or rest. Preoperative and postoperative thoracolumbar steel underwire corsets were given to all patients. PVP was applied to the patients with VCFs, whose fracture age was 10 weeks. PVP was not performed in patients with motor and sensory loss, incontinence, and unstable vertebral fractures.

All patients were preoperatively evaluated through vertebral magnetic resonance imaging (MRI), X-ray or computed tomography (CT). These procedures were performed in the operating room under sedo-anesthesia. All patients were placed in prone position with scopy guidance. Antibioprophylaxis (1 gm cefazolin sodium intravenously) was given before the procedure. The 11-gauge Jamshidi biopsy needle was percutaneously inserted into the fractured vertebral body via the transpedicular approach. A cannula was placed in the back half of the spine body with the help of Kirschner wires. A bone biopsy was obtained by inserting and twisting an obturator. An attempt was made for bone biopsy from the vertebral corpus in all patients. However, adequate biopsy was obtained from 67 of 87 patients. Bone cement was injected into the vertebra through the pedicle. Follow-up for complications after PVP was performed through postoperative vertebral radiography or vertebral CT.

Table 1. Demographic and clinical characteristics of patients undergoing routine biopsy during percutaneous vertebroplasty

\begin{tabular}{ll|}
\hline Study population & Patients $(\mathrm{n}=67)$ \\
\hline Age $($ years, mean \pm SD) & $74.18 \pm 9.08$ \\
\hline Gender $(\mathrm{n}, \%)$ & $\begin{array}{l}\text { Male } 12(17.91 \%) \\
\text { Female 55 }(82.09 \%)\end{array}$ \\
\hline Vertebral tumors $(\mathrm{n}, \%)$ & \\
\hline Multiple myeloma & $2(2.99 \%)$ \\
\hline Renal cell carcinoma metastasis & $1(1.49 \%)$ \\
\hline SD: Standard deviation & \\
\hline
\end{tabular}

\section{RESULTS}

Tumor pathology was detected in 3 patients except osteoporosis. This means that $4.48 \%$ of patients undergoing bone biopsy were pathological. They were multiple myeloma (MM) and renal cell carcinoma (RCC) metastasis. Other specimens showed necrotic bone areas, hematopoietic areas, acute or chronic inflammation foci. Our first patient with MM was a 61-year-old man. He had previously had suspected tumors but could not be diagnosed. Pathological fractures were present in the T6/T11/L3 vertebrae. Diagnosis was made by vertebral bone biopsy. The second patient with MM was a 62-year-old woman. Previously, another surgeon had done T12 and L4 pvp. However, biopsy was not taken in the previous surgery. The L2/L5 had new VCFs. PVP was applied to both spine. Biopsy was performed and diagnosis was made. Figure 1 shows L2 and L5 VCFs on preoperative sagittal MRI sections of a 62-year-old woman with MM (Figure 1). The other patient was a 64-year-old female patient. She underwent surgery for RCC years ago. No metastasis was detected during follow-up. However, she was admitted to our clinic because of severe low back pain. Lumbar MRI showed many metastases, especially L4 vertebrae. This patient underwent bone biopsy during PVP. The diagnosis was made through a biopsy. In male patient with MM, the lesions were suspected because of the history of previous tumor investigations. However, there was no doubt in the female patient before PVP. The female patient was diagnosed incidentally. The patient with other RCC metastasis had suspected tumor due to his history. Therefore, the incidence of incidental tumors was $1.49 \%$ in routine vertebral biopsy performed during PVP.

\section{DISCUSSION}

Minimally invasive spine augmentation methods such as PVP are frequently used in the treatment of VCFs, especially in the thoracolumbar region. PVP and percutaneous kyphoplasty (PKP) are often used to treat osteoporotic vertebral compression fractures ${ }^{(3,13)}$. It has been applied successfully even in burst fractures without neurological deficit ${ }^{(9)}$. However, the cause of low back and back pain may not be caused solely by osteoporosis. Differential diagnosis should include benign or

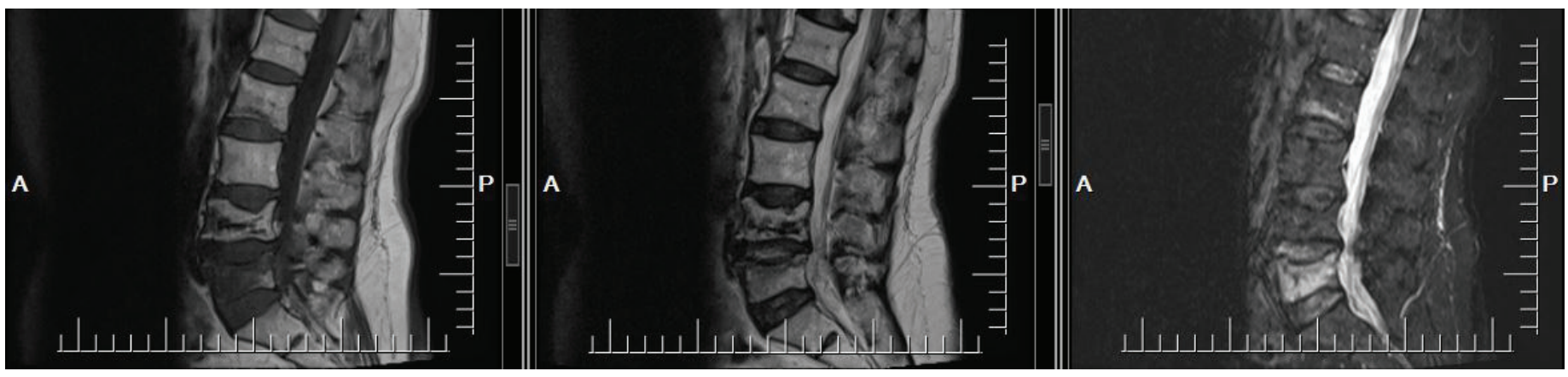

Figure 1. T1-weighted, T2-weighted, and fat suppression sagittal magnetic resonance imaging show the involvement, compression, and edema of the vertebral body at L2/L5 levels 
malignant tumors, traumas, infections, tumor endocrinopathy, blood dyscrasias, and autoimmune diseases ${ }^{(4,11)}$.

$\mathrm{MM}$ is a hematologic malignancy with lytic bone lesions. Vertebral involvement is present in approximately $60 \%$ of MM patients. PVP has been safely administered and recommended for the treatment of pain in these patients ${ }^{(8)}$. RCC is the most common malignancy of the kidney. Recurrence postoperatively occurs in $40 \%$ of patients ${ }^{(14)}$. Treatment options for vertebral metastases of RCC are limited. If metastasis is detected, the average life expectancy is $12-24$ months. PVP is used to relieve pain and support the vertebral body ${ }^{(5)}$. In the literature, vertebral metastasis of RCC has been reported less than vertebral involvement of MM. Diagnosis of spinal metastasis requires a good clinical evaluation (patient age, single and multiple involvement, history), CT, MRI, and nuclear medicine ${ }^{(2)}$. Nuclear medicine methods, such as bone scintigraphy, show all vertebral fractures. Bone scans are insufficient to reveal the underlying pathology in fractures. MRI is the most appropriate method to show whether the vertebral fracture is old or new and the probability of tumor. It is also guiding for the choice of treatment. However, despite all these investigations and findings, bone biopsy is needed if the suspicion continues ${ }^{(11)}$. In a study published in 2005, biopsy was taken from 142 patients and plasma cell dyscrasia was detected in 4 (2.82\%) patients. Therefore, the authors recommended biopsy during vertebral augmentation procedure. In this study, the majority of patients were women and the mean age of all patients was 72 years (range 40-90 years) ${ }^{(12)}$. In this study, age, gender and MM rates coincide with the results of our study. In 2010, a research was carried out at a public hospital in Greece. It was thought to increase the cost in patients without suspected malignancy. Therefore, biopsy should be performed only in patients with suspected malignancy. Routine vertebral bone biopsy was not recommended due to $\operatorname{cost}^{(11)}$. In another article published in the UK in 2014, malignancy was detected in 4 (4.7\%) of 86 patients who had no previous history of cancer. Malignancy was seen in $2(10 \%)$ of 20 patients with cancer history. When both groups were combined, the diagnosis of malignancy reached the rate of $5.5 \%$. The authors recommended vertebral bone biopsy with or without cancer in both groups ${ }^{(7,10)}$. The results of this study conducted at Royal London Hospital are consistent with the results of the research conducted in our hospital.

Procedures were performed by a surgeon who believed that a routine biopsy was required during vertebroplasty. This made our work easier. Therefore, the study was retrospectively reviewed. When we look at the literature, we see that there are similar studies but they are limited. We did this study to contribute to the literature and to guide surgeons dealing with the spine ${ }^{(10)}$.

\section{CONCLUSION}

In conclusion, we recommend routine bone biopsy during percutaneous vertebral augmentation. If the cost is low, it should be done to all patients. If the cost is high, it should be done to patients with a history of cancer and suspected cancer. It is an advantage that it does not extend working time and can be applied easily.

\section{Ethics}

Ethics Committee Approval: Permission from Chief Physicsian to use data (approval number: 20.08.2019/348)

Informed Consent: Retrospective study.

Peer-review: Internally peer-reviewed.

\section{Authorship Contributions}

Surgical and Medical Practices: Ö.Ö., Concept: Ö.Ö., N.K., Design: Ö.Ö., N.K., Data Collection or Processing: Ö.Ö., N.K., Analysis or Interpretation: Ö.Ö., N.K.,Literature Search: Ö.Ö., N.K., Writing: Ö.Ö., N.K.

Conflict of Interest: No conflict of interest was declared by the authors.

Financial Disclosure: The authors declared that this study received no financial support.

\section{REFERENCES}

1. Constantin C, Albulescu DM, Diţă DR, Georgescu CV, Deaconu AC. Vertebral body clinico-morphological features following percutaneous vertebroplasty versus the conservatory approach. Rom J Morphol Embryol 2018;59:159-64.

2. Guarnieri G, Izzo R, Muto M. Current trends in mini-invasive management of spine metastases. Interv Neuroradiol 2015;21:263-72.

3. Health Quality Ontario. Vertebral augmentation involving vertebroplasty or kyphoplasty for cancer-related vertebral compression fractures: a systematic review. Ont Health Technol Assess Ser 2016;16:1-202.

4. Kırcelli A, Çöven I. Percutaneous balloon kyphoplasty vertebral augmentation for compression fracture due to vertebral metastasis: a 12-month retrospective clinical study in 72 patients. Med Sci Monit 2018;4:2142-8.

5. Langdon J, Way A, Heaton S, Bernard J, Molloy S. The management of spinal metastases from renal cell carcinoma. Ann R Coll Surg Engl 2009;91:649-52.

6. Muijs SP, Akkermans PA, van Erkel AR, Dijkstra SD. The value of routinely performing a bone biopsy during percutaneous vertebroplasty in treatment of osteoporotic vertebral compression fractures. Spine 2009;34:2395-9.

7. Mukherjee S, Thakur B, Bhagawati D, Bhagawati D, Akmal S, Arzoglou V. Utility of routine biopsy at vertebroplasty in the management of vertebral compression fractures: a tertiary center experience. J Neurosurg Spine 2014;21:687-97.

8. Nas ÖF, İnecikli MF, Hacıkurt K, Büyükkaya R, Özkaya G, Özkalemkaş F. Effectiveness of percutaneous vertebroplasty in patients with multiple myeloma having vertebral pain. Diagn Interv Radiol 2016;22:263-8.

9. Ozsoy KM, Oktay K, Gezercan Y, Cetinalp NE, Okten Al, Erman T. Percutaneous vertebroplasty for the treatment of osteoporotic thoracolumbar fractures with posterior body involved in elderly patients. Turk Neurosurg 2019;29:90-4.

10. Pagdal SS, Nadkarni S, Hardikar SM, Hardikar MS. Role of transpedicular percutaneous vertebral biopsy for diagnosis of pathology in vertebral compression fractures. Asian Spine J 2016;10:925-9.

11. Pneumaticos SG, Chatziioannou SN, Savvidou C, Pilichou A Rontogianni D, Korres DS. Routine needle biopsy during vertebral augmentation procedures. Is it necessary? Eur Spine J 2010;19:1894-8. 
12. Togawa D, Lieberman IH, Bauer TW, Reinhardt MK, Kayanja MM. Histological evaluation of biopsies obtained from vertebral compression fractures: unsuspected myeloma and osteomalacia. Spine 2005;7:781-6.

13. Yuan WH, Hsu HC, Lai KL. Vertebroplasty and balloon kyphoplasty versus conservative treatment for osteoporotic vertebral compression fractures: a meta-analysis. Medicine (Baltimore) 2016;95:e4491.
14. Zerlauth JB, Meuli R, Dunet V. Renal cell carcinoma metastasis involving vertebral hemangioma: dual percutaneous treatment by navigational bipolar radiofrequency ablation and high viscosity cement vertebroplasty. BMJ Case Rep 2017;2017. pii: bcr2016012931.

15. Zhang L, Li J, Yang H, Luo Z, Zou J. Histological evaluation of bone biopsy results during PVP or PKP of vertebral compression fractures. Oncol Lett 2013;5:135-8. 